\title{
A etiologia da "cara inchada", uma periodontite epizoótica dos bovinos $^{1}$
}

\author{
Jürgen Döbereiner ${ }^{2}$, Iveraldo dos Santos Dutra ${ }^{3}$ e Ivan Valadão Rosa ${ }^{4}$
}

\begin{abstract}
Döbereiner J., Dutra I.S. \& Rosa I.V. 2004. [The etiology of "cara inchada", a bovine epizootic periodontitis in Brazil.] A etiologia da "cara inchada", uma periodontite epizoótica dos bovinos. Pesquisa Veterinária Brasleira 24(1):50-56. Projeto Sanidade Animal Embrapa/ UFRRJ, Embrapa-CNPAB/PSA, Seropédica, RJ 23851-970, Brazil. E-mail: jurgen@ ufrrj.br

A condensed version in Portuguese of an extensive review on "cara inchada"-periodontitis of cattle, published in English, is presented with some additional information. This disease was responsible for severe losses of young cattle especially in the 1970's and 1980's in central Brazil. Due to the progressive periodontitis and the loss of teeth, the animals cannot eat properly, loose condition and may die. This was believed to be due to mineral deficiency or imbalance. However, field and laboratory observations and experiments over 30 years showed that it is a multifactorial infectious disease which can be defined as Bovine Epizootic Periodontitis. It was concluded that there are three main factors required for its development: (1) Cattle affected are at the age when premolar and molar teeth erupt; (2) bacteria of the Bacteroides group are present in the subgingival spaces; (3) the ingestion with the forage of subinibitory concentrations of antibiotics, mainly streptomycin, produced by the large increase in the number of actinomycetes found in soils from pastures sown after recently cleared forest; this leads to an increased adherence of Bacteroides spp to the gingival epithelium and to the progressive destruction of the periodontal tissues. Nowadays, the disease has practically disappeared, because the disturbed soil microflora has reached the new equilibrium, and the occupation of virgin land for cattle raising has almost ceased. New outbreaks may occur with former problem-pastures when these are freshly cultivated as this again leads to a disequilibrium of the soil microflora and to increased antibiotic production. Other antibiotics such as spiramycin and virginiamycin, administered orally or added to a mineral supplement, can control the disease.
\end{abstract}

INDEX TERMS: “Cara inchada”, periodontitis, cattle.

RESUMO.- Uma versão condensada em português de um artigo de revisão sobre a periodontite da "cara inchada" dos bovinos, publicado em inglês, está apresentada com algumas informações adicionais. A doença foi responsável por grandes perdas de bovinos jovens, principalmente nas décadas de 1970 e 1980 no Brazil

\footnotetext{
${ }^{1}$ Recebido em 10 de novembro de 2003.

Aceito para publicação em 18 de dezembro de 2003.

${ }^{2}$ Embrapa Agrobiologia, Projeto Sanidade Animal Embrapa/UFRRJ, Km 47, Seropédica, RJ 23851-970; pesquisador bolsista do CNPq (305294/881). E-mail: jurgen@ufrrj.br

${ }^{3}$ Curso de Medicina Veterinária/DAPSA, Unesp-Araçatuba, Cx. Postal 533, Araçatuba, SP 16015-050. E-mail: isdutra@ fmva.unesp.br

${ }^{4}$ Fazenda Bonança, Cx. Postal 151, Pereira Barreto, SP 15370-000; exPesquisador da Embrapa Gado de Corte, Campo Grande, MS. E-mail: ivanvaladao@bol.com.br
}

Central. Em face da periodontite progressiva e a perdas de dentes, os animais não podem se alimentar convenientemente, tornam-se emaciados e podem morrer. A doença foi tida como uma deficiência ou desequilíbrio mineral. Mas as pesquisas de campo e de laboratório, realizadas durante 30 anos, mostraram que trata-se de doença infecciosa multifatorial a ser definida como Periodontite Epizoótica Bovina. Chegou-se à conclusão que os fatores principais para o seu desenvolvimento são: (1) a idade dos bovinos na fase de erupção dos dentes premolares e molares; (2) a presença de bactérias do grupo Bacteroides spp nos espaços subgengivais; e (3) a ingestão com a forragem de concentrações subinibitórias de antibióticos, sobretudo de estreptomicina, produzidos por actinomice-tos cujo número é aumentado em solos virgens recém-cultivados na formação de pastagens após a derrubada da mata ou da vegetação de Cerrado; isto leva a um aumento da aderência 
dos bacteróides ao epitélio gengival e à destruição dos tecidos peridentários. Hoje em dia, a doença perdeu a sua importância e praticamente desapareceu, porque a microbiota do solo entrou novamente em equilíbrio e a abertura de grandes áreas virgens para a pecuária cessou. Porém, novos surtos podem ocorrer em áreas anteriormente positivas para a doença quando, na reforma de pastagens ou capineiras, houver um novo desequilíbrio da microbiota do solo. Outros antibióticos, como a espiramicina e virginiamicina, administrados por via oral ou adicionado a misturas minerais, podem controlar a periodontite.

TERMOS DE INDEXAÇÃO: “Cara inchada”, periodontite, bovinos.

O PRESENTE TÓPICO se baseia no extenso artigo de revisão sobre a "cara inchada" dos bovinos ( $\mathrm{Clb}$ ) que foi publicado em inglês (Döbereiner et al. 2000). Em face da idéia bastante generalizada e ainda presente no meio veterinário, de que a Clb seria causada por desequilíbrio ou deficiência mineral (Fig.1), torna-senecessário publicar ainda esteartigo.

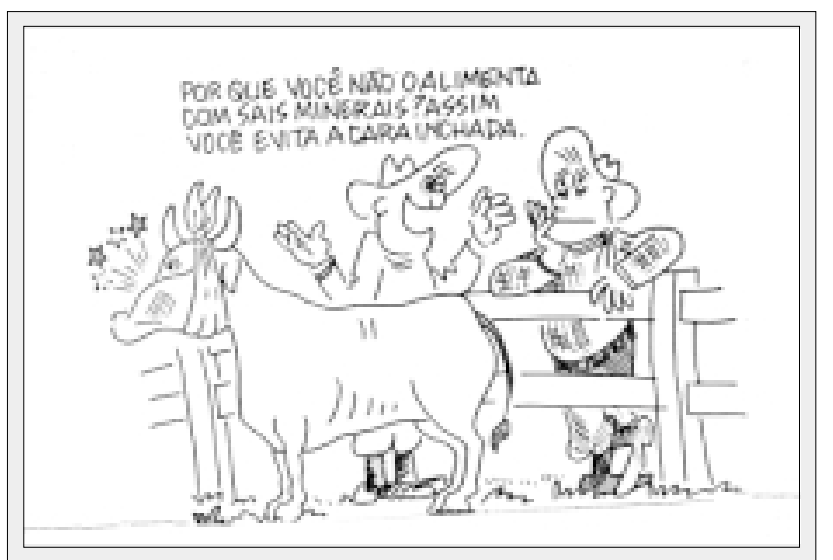

Fig. 1. Este desenho demonstra como é amplamente difundida a idéia equivocada de que uma deficiência ou desequilíbrio mineral ser a causa da "cara inchada" dos bovinos (Clb).

A Clb foi inicialmenterelatadanos Estados de Minas Gerais eSão Paulo mas, naépoca, foi tida como necrobacilose (Giovineet al. 1943, Lamounier \& Pereira 1945). Com a abertura de grandes áreas de vegetação natural para 0 desenvolvimento da pecuária no Sudeste, Centro-Oeste e Norte do Brasil, a Clb tornou-se a mais importante enfermidade dos bovinos nestas regiões. A doença ocorreu nos pastos de capim-colonião (Panicum maximum) recém-formados após a derrubada da mata (Döbereiner et al. 1974). Mais tarde, com o cultivo também do Cerrado, região considerada atéentão indene, a Clb incidiu em pastos de capim-braquiária (Brachiaria decumbens). As perdas econômicas causadas pela Clb foram muito elevadas, pois a doença atingiu, na primeira fase, mais de $60 \%$ dos bezerros. Os bovinos afetados que não morreram na idadejovem, se tornaram animais magros ede pouco desenvolvimento corporal pertencendo ao refugo dos rebanhos. Muitos pecuaristas foram obrigados a mudar o seu sistema de produção e desistir de criar bezerros em fazendas dealta prevalência da doença.
A Clb é bem distinta da "cara inchada" dos eqüinos (Cle). É amplamente conhecido que a Cle é causada por um desequilíbrio de cálcio e fósforo na alimentação, desenvolvendo-se a osteodistrofia fibrosa, sobretudo em potros e éguas em gestação ou aleitamento. Existe, neste caso, falta de calcificação do tecido osteóide e proliferação compensatória de tecido conjuntivo fibroso, 0 que resulta em abaulamento bilateral simétrico da face, sem processo inflamatório peridentário.

Consoante com o que se observa nos eqüinos, Nunes et al. (1979) consideraram a Clb como sendo uma osteodistrofia fibrosa; mas, a Clb caracteriza-se por uma periodontite purulenta, de rápida progressão, com abaulamento uniou bilateral da face em conseqüência de periostite crônica ossificante, 0 que resulta em aposição lateral de tecido ósseo nos maxilares (Fig. 2 a 5) e, mais raramente, na mandíbula. A doença freqüentemente está acompanhada de diarréia que agrava o quadro clínico. 0 coeficiente de letalidade é alto. Lesões incipientes da periodontite já podem se desenvolver em bezerros a partir de 1 mês de idade, logo após a erupção dos dentes prémolares e a formação das papilas interdentárias. Estas lesões são geralmente localizadas entre os segundos e terceiros pré-molares maxilares (Fig. 6). 0 ápice da papila gengival está sendo destruído e, em poucos dias, se forma uma bolsa peridentária contendo restos alimentares e material untuoso de mau cheiro, típico do cultivo das bactérias anaeróbias isoladas destas lesões (Fig. 7). 0 processo inflamatório da gengiva marginal resulta na destruição dos alvéolos, afrouxamento e perda de dentes (Fig. 8). Em bezerros de "sobre-ano", introduzidos em pastos positivos para Clb, observam-se as lesões peridentárias entre os últimos pré-molares e primeiros molares, o que indica que a periodontite se desenvolve somente durante a fase de erupção e crescimento dos dentes. Se os bovinos jovens afetados permanecem em pastos positivos para $\mathrm{Clb}$ e tornam-se adultos, a periodontite pode, por continuação do processo inflamatório, se alastrar ao nível dos molares (Fig. 9). (Döbereiner et al. 1974)

Os experimentos realizados na década de 1970, em duas fazendas com alta incidência de Clb no Mato Grosso do Sul, revelaram que a suplementação com mistura mineral considerada completa não preveniu a doença (J.C.Sousa et al., Embrapa Gado de Corte, dados não publicados). Baseado nestes resultados experimentais e em outros dados, não há nenhuma evidência que indique uma relação entre a $\mathrm{Clb}$ e desequilíbrio ou deficiência mineral ( Moraes et al. 1994, Rosa \& Döbereiner 1994).

A fim de verificar possíveis alterações primárias ou secundárias do esqueleto, as quais poderiam ter influência sobre o desenvolvimento de alterações alveolares, foram realizados estudos histológicos e microrradiográficos de costelas de 17 bezerros, com 2 a 6 meses de idade, e de três bezerros de 7 a 10 meses, todos afetados pela $\mathrm{Clb}$. Nenhum sinal de osteodistrofia fibrosa, de um hiperparatireoidismo secundário no desequilíbrio de cálcio e fósforo, foi encontrado. Também não foram encontrados sinais de deficiência de fósforo, tais como raquitismo e osteomalácia. Pela comparação das alterações da osteogênese reduzida e do desenvolvimento condral retardado, encontradas nos dois grupos de bezerros, concluiu-se que as alterações ósseas da Clb são de natureza secundária, conseqüên- 

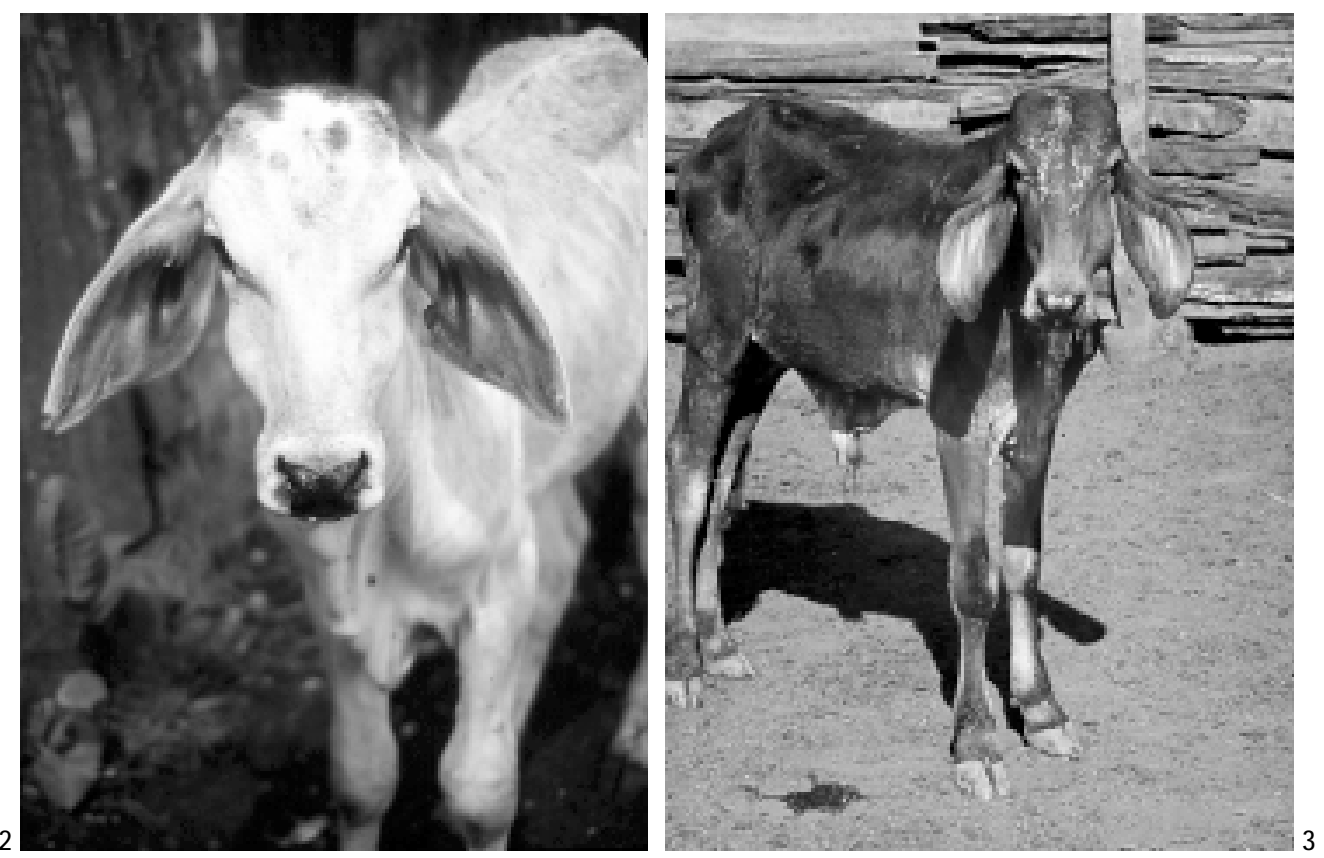

Fig. 2. A Clb resulta nos animais jovens em abaulamento geralmente bilateral da face, em conseqüência da periodontite.

Fig. 3. 0 abaulamento pode ser unilateral, se a periodontite afeta somente um lado da arcada dentária, o que é um indício que as alterações não são de natureza sistêmica.

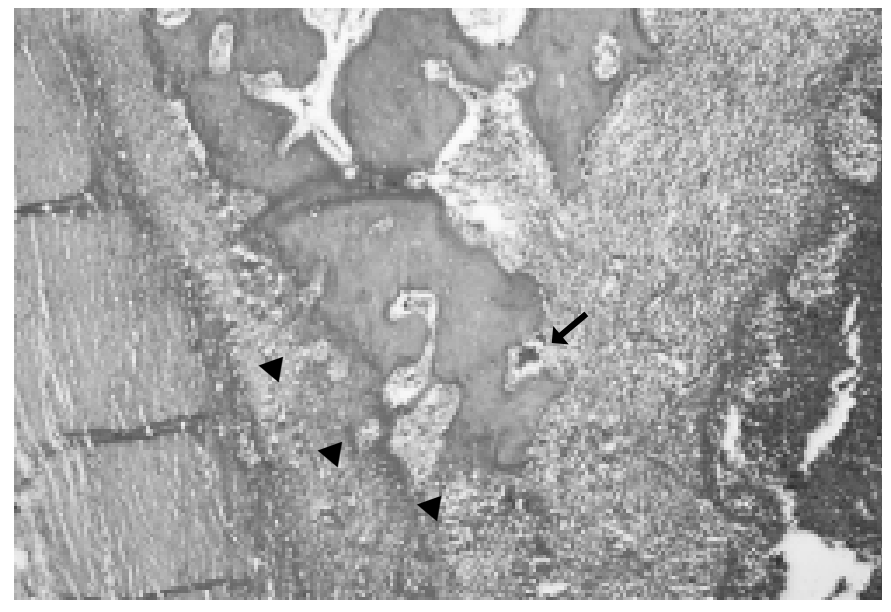

Fig. 4. A periodontite purulenta (à direita) resulta na absorção óssea, evidenciada pela presença de osteoclasto (seta), e numa periostite crônica ossificante com aposição óssea lateral (pontas de seta). HE, obj.10.

cia da doença debilitante, e não podem ser consideradas como fator desencadeante da periodontite. Assim, não se deve postular que uma atrofia do bordo do alvéolo abriria uma porta de entrada para a infecção bacteriana (Döbereiner $\&$ Dämmrich 1997). Também não foram encontradas alterações do colágeno que pudessem diminuir a integridade da gengiva marginal (Seifert et al. 1983).

Os relevantes estudos dos aspectos bacteriológicos da Clb mostraram a natureza infecciosa da doença. Das lesões peridentárias foram isoladas, proporcionalmente em

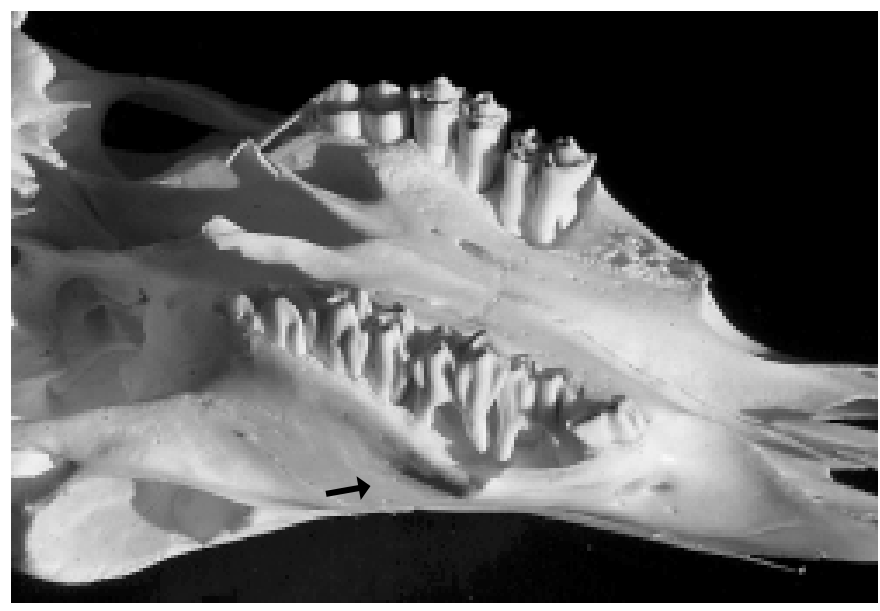

Fig. 5. 0 crânio macerado de um bovino de "sobre-ano" revela a destruição de alvéolos e o abaulamento lateral do osso maxilar esquerdo ao nível do terceiro dente pré-molar (seta), em conseqüência da periodontite e da periostite ossificante da Clb.

grande quantidade, bactérias do grupo Bacteroides spp pigmentados de negro (Bacteroides melaninogenicus) ${ }^{5}$, acompanhadas de Actinomyces (Corynebacterium) pyogenes. Esses bacteróides também foram isolados, em pequeno número, do espaço subgengival de bovinos sadios (Blobel et al. 1984).

Tendo em conta as evidências da etiologia infecciosa do processo peridentário, cabe a pergunta: como os bacteróides

5Ultimamente, Shah \& Collins (1990) propuseram a reclassificação destes bacteróides pigmentados. 


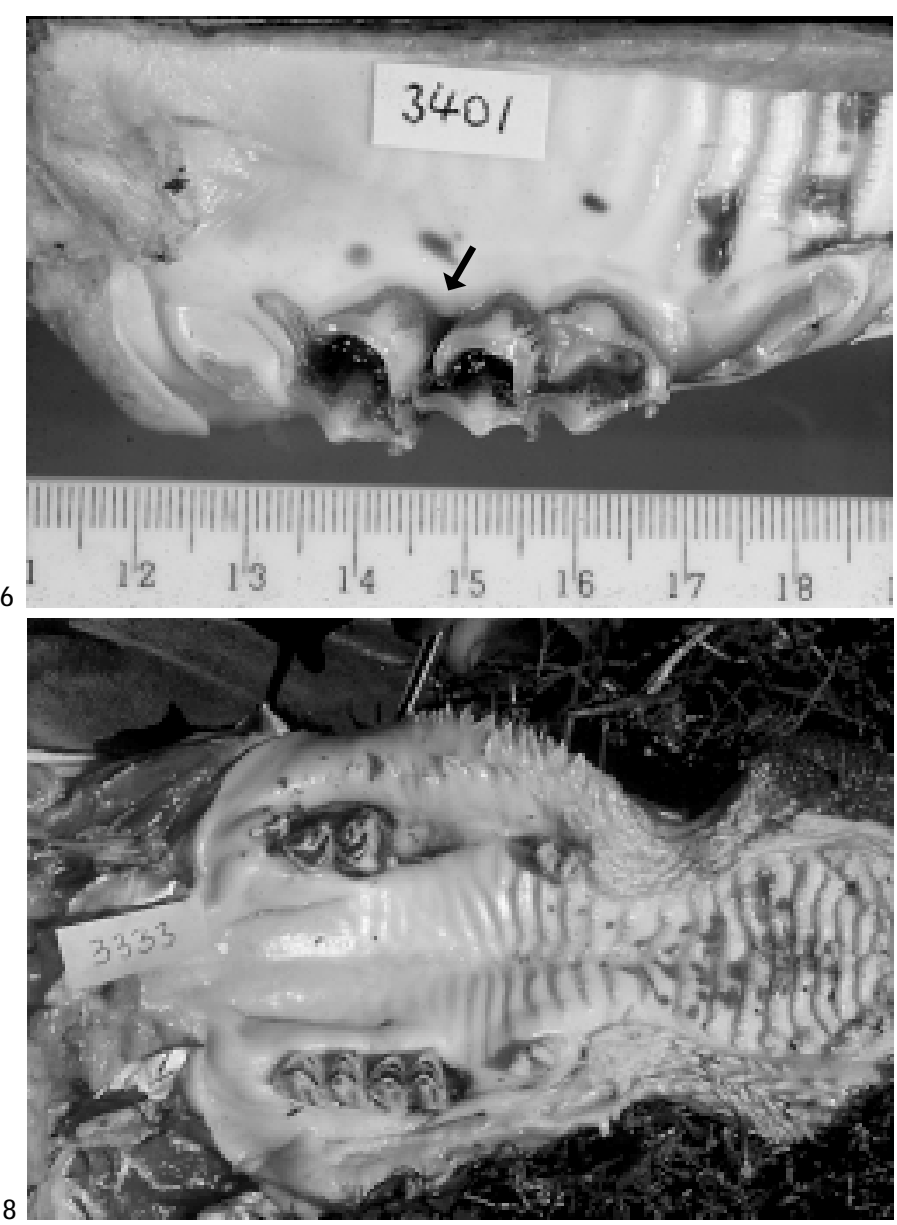

Fig. 6. Lesão incipiente da periodontite da $\mathrm{Clb}$ com a perda do ápice da papila gengival entre 0 segundo e o terceiro dentes pré-molares maxilares esquerdos (seta) de bezerro com cerca de 45 dias de idade. A periodontite inicia-se ao nível de dentes em erupção; assim que em bezerros com mais idade, introduzidos em fazendas positivas para a doença, a lesão inicial é observada na altura dos dentes molares que ainda não são completamente irrompidos.

Fig. 8. Após a perda de dentes, as lesões peridentárias da $\mathrm{Clb}$ tendem para cura (Bovino com 18 meses de idade).

podem-se tornar patogênicos e tão rapidamente destruir o aparelho peridentário? Uma importante indicação veio das observações de pecuaristas, que informaram que quando transferiam os bovinos afetados pela $\mathrm{Clb}$ para fazendas indenes no Estado de São Paulo, os animais se recuperavam. Para comprovar a veracidade desta informação, um lote de bovinos com Clb foi transferido do Vale do Jurigue, região de Rondonópolis, para uma fazenda situada no Cerrado natural de Itiquira, Mato Grosso, na qual o sal comum era o único suplemento; pois a $\mathrm{Clb}$ nunca tinha sido observada em propriedades com pastos naturais. Já 2 meses após a transferência dos bovinos doentes para esta região indene, o odor pútrido das lesões peridentárias diminuiu e, 3 meses mais tarde, a periodontite em todos os bovinos tinha-se curado; os animais ganharam aspecto bom de nutrição, houve epitelização das lesões peridentárias e os dentes, antes frouxos, se firmaram dentro dos alvéolos. Este resultado de recuperação dos bovinos no Cerrado natural for-
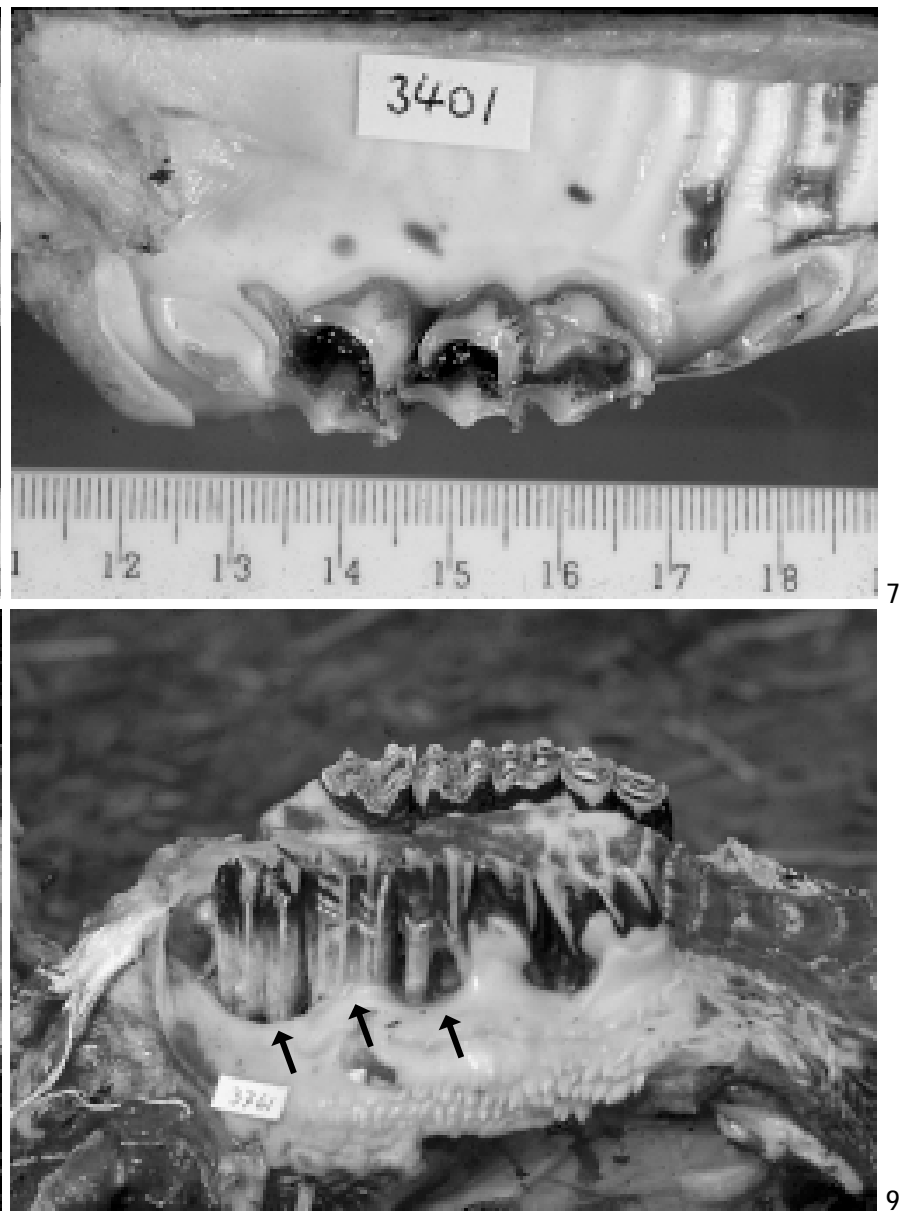

Fig. 7. Lesão peridentária da Clb mais avançada com destruição de toda a papila interdentária entre o segundo e o terceiro dentes prémolares maxilares, e acúmulo de restos alimentares (retirados), de bezerro com 1 mês de idade.

Fig. 9. Se os bovinos afetados pela Clb permanecem nos pastos positivos para a doença até a idade adulta, a periodontite pode atingir o tecido peridentário dos molares (setas).

neceu 0 indício da presença de um fator desenca-deante da periodontite nos pastos recém-formados e positivos para Clb. (Döbereiner et al. 1975)

O experimento de transferência para o Cerrado de Itiquira foi, de certa maneira, repetido pela transferência de bezerros com $\mathrm{Cl}$ do município de Campos Novos Paulista e Santa Rosa do Viterbo, SP, para o "Km 47", Seropédica, RJ (Dutra et al. 1999). 0 resultado da transferência foi que estes animais se recuperaram, da mesma maneira, dentro de poucos meses (Fig. 10).

Como a Clb incidia em pastos com diferentes espécies de gramíneas (Panicum maximum, Brachiaria decumbens) e tendo-se excluído plantas invasoras (Döbereiner et al. 1976) ou a queima da vegetação como possíveis fatores para a ocorrência da doença (Döbereiner et al. 1978), concluiu-se que o fator desenca-deante da $\mathrm{Clb}$ deveria estar ligado a particularidades do solo.

Foram realizados experimentos que corroboraram com a hipótese da existência desse fator desencadeante da $\mathrm{Cl} b$ na pas- 


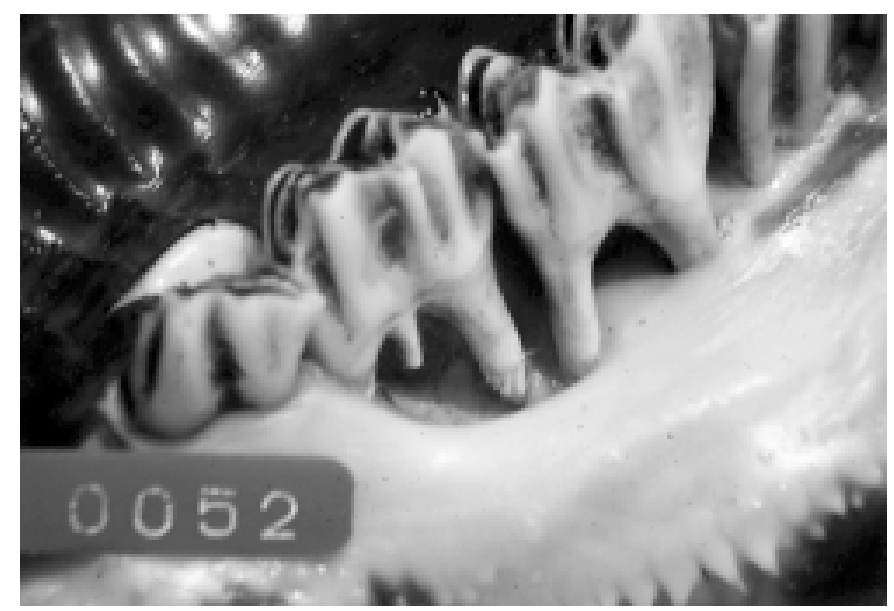

Fig. 10. Houve cura da periodontite em bezerros afetados após transfência para região indene, como os trazidos do município Campos Novos Paulista, SP, para o nosso Instituto no "Km 47", Rio de Janeiro.

tagem. Assim, bezerros afetados pela periodontite foram colocados em currais de duas fazendas positivas para a doença e alimentados com concentrados e capim de Cerrado natural existente dentro destas propriedades. Do mesmo modo como aconteceu com o lote transferido para o Cerrado de Itiquira, os animais isolados dos pastos positivos para $\mathrm{Clb}$, através da estabulação no curral das duas fazendas, se recuperaram dentro de poucos meses (Rosa et al. 1976).

Como os bezerros já podem adoecer com um mês de idade quando a sua alimentação ainda consiste na maior parte de leite, foi realizado um experimento para testar se o fator desenca-deante da Clb passaria pelo leite materno. Este experimento foi realizado no curral de uma das fazendas onde bezerros com $\mathrm{Cl}$ e e isolados do pasto positivo para a doença se tinham recuperado no ano anterior (Rosa et al. 1976). Cinco bezerros com Clb foram recolhidos neste curral, receberam capim do Cerrado natural e foram aleitados por suas mães, mantidas em pasto positivo para a doen-

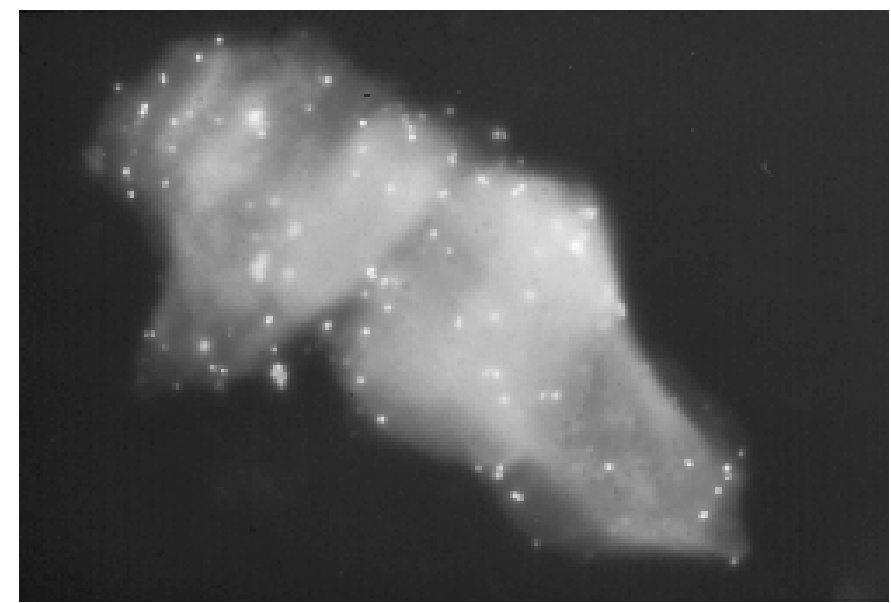

Fig. 11. Aumento da aderência de Bacteroides spp pigmentados de negro a células epiteliais da gengiva bovina, quando as bactérias foram pré-tratadas com concentração subinibitória de estreptomicina. Isocianato de fluoresceina, obj.100. ça e trazidas duas vezes por dia ao curral. Estes bezerros não se recuperaram da $\mathrm{Clb}$, indicando que 0 fator desencadeante da periodontite passa pelo leite (Döbereiner et al. 1987).

0 que trouxe nova luz na procura do fator que provocaria o desencadeamento do processo inflamatório peridentário, foi um trabalho sobre a modificação da microbiota em solo de Cerrado cultivado pela primeira vez com o plantio de soja após a derrubada da vegetação natural (Baldani et al. 1982). Estes autores relataram que as estirpes de Rhizobium (Bradyrhizobium sp) nos nódulos radiculares da soja foram pouco eficientes na fixação biológica de nitrogênio sob as condições de solo virgem de Cerrado recém-cultivado. Verificaram que, nessas condições do primeiro cultivo, há um aumento do número de actinomicetos no solo, entre estes os do gênero Streptomyces (Huddleston et al. 1997), e uma maior eficácia da fixação de nitrogênio por rhizóbia resistentes à estreptomicina. Concluiu-se que nos solos virgens recém-cultivados há um aumento da produção de antibióticos, especialmente de estreptomicina. Estes fatos se enquadravam muito bem no que acontece na formação de pastagens em áreas recém-abertas e a ocorrência da $\mathrm{Cl} b$.

$\mathrm{Na}$ procura do fator desencadeante da periodontite da Clb estudou-se então a possível influência de doses subinibitórias de estreptomicina sobre a aderência de bactérias isoladas das lesões peridentárias (Kopp et al. 1996). Verificou-se, por ensaios in vitro, que concentrações subinibitórias de estreptomicina aumentaram significativamente a aderência de bacteróides pigmentados de negro a células epiteliais de gengiva bovina. Nesse ensaio o aumento foi de 10 vezes, isto é, de 0,4 para 4,0 bacteróides aderidas por célula epitelial (Fig. 11). Este aumento de aderência ao epitélio do espaço subgengival permite a colonização das bactérias, tornando-as patogênicas pela produção de enzimas e endotoxinas com grande potencial de destruição dos tecidos peridentários (Dutra et al. 1986). Foi verificada ainda a produção de actinomicina nesses solos, que é um antibiótico com o mesmo efeito de aumento da aderência das bactérias ao epitélio gengival (Grassmann et al. 1997).

Page \& Schroeder (1982), no seu livro “Periodontitis in Man and Other Animals", salientam que sem colonização de bactérias na gengiva marginal, as lesões peridentárias não podem se desenvolver. Estes mesmos autores escrevem nesta sua revisão, referindo-se à Clb: “Deve se mencionar que as alterações desta periodontite, encontradas a nível dos prémolares e molares, são típicas daquelas causadas por infecção, especialmente quando consideradas sob o ponto de vista da patologia comparada".

Para verificar o efeito de injeções de antibióticos de ação prolongada sobre as lesões peridentárias da $\mathrm{Clb}$, foram realizados dois experimentos, um com Penicilina G + Estreptomicina e o outro, com Tetraciclina (Rosa et al. 1985). A administração parenteral destes antibióticos de ação prolongada, nas doses utilizadas, mostrou-se ineficaz para o tratamento da periodontite.

No intuito de encontrar métodos de profilaxia da $\mathrm{Clb}$, foram realizados experimentos em duas fazendas positivas para a doença, adicionando-se espiramicina ao suplemento mineral, na proporção de 25 a $50 \mathrm{~g}$ do antibiótico para $50 \mathrm{~kg}$ da mistura 
mineral de rotina utilizada na propriedade ((Döbereiner et al. 1990). Este antibiótico é usado pela odontologia humana e foi escolhido por sua alta concentração na saliva dos animais tratados. Foi colocada à disposição dos lotes de controle a mistura mineral sem 0 antibiótico. Os bezerros, com as suas mães, entraram nos experimentos antes de completarem 15 dias de idade. Repetidos exames da gengiva destes bezerros, o último realizado quando eles tinham 7 a 8 meses de idade, não revelaram nenhuma lesão da gengiva nos lotes "mistura mineral com espiramicina" (de 65 e 168 vacas com os seus bezerros), mas mostraram lesões peridentárias típicas da Clb nos lotes "mistura mineral sem espiramicina" (de 65 e 274 vacas com os seus bezerros) em 5,1 e 10,8\%dos bezerros, respectivamente.

Para verificar a eficácia de virginiamicina, antibiótico de reduzida absorção pelo tubo digestivo, na profilaxia da $\mathrm{Clb}$, foram realizados dois experimentos numa mesma fazenda com prevalência da doença de $51,1 \%$ no ano anterior. No primeiro experimento, 30 bezerros recém-nascidos, mantidos no mesmo regime de pasto com os 30 bezerros de controle, receberam $0,032 \mathrm{~g}$ de virginiamicina por via oral, duas vezes por semana. Repetidos exames durante 5 meses revelaram ausência de lesões peridentárias no grupo tratado, mas 30 \%de periodontite nos controles. No segundo experimento, com duração de 6 meses, foi colocado à disposição de 150 bezerros jovens um suplemento mineral contendo virginiamicina como aditivo. Nenhum dos animais desenvolveu $\mathrm{Clb}$; mas quando mais tarde, durante 4 meses, foi utilizada a mistura mineral sem o antibiótico, apareceram lesões peridentárias em 20 \%dos bezerros. Essas duas séries de experimentos, com a administração de antibióticos por via oral, revelaram que a sua adição na mistura mineral é medida profilática eficaz para evitar a Clb. (Dutra et al. 1992, Tims et al. 1992)

Diante de todos estes resultados de pesquisa pode-se concluir que a $\mathrm{Clb}$ é uma doença infecciosa multifatorial, desencadeada pela modificação da microbiota do solo em áreas virgens recém-cultivadas. 0 desaparecimento da $\mathrm{Clb}$ pode ser explicado pelo fato de que a microbiota do solo entrou novamente em equilíbrio e o fator desencadeante da periodontite deixou de existir.

Uma nova evidência, para essa interpretação, obtivemos em propriedades de gado leiteiro nos municípios de Santa Rosa do Viterbo e São Simão, Estado de São Paulo. Nos anos de 1987 a 1989, a prevalência da periodontite da Clb em sete propriedades variava de 18 a 90\% Em visita posterior, realizada em 2003, constatamos que em todas estas propriedades a doença havia desaparecida em poucos anos. Este desaparecimento da $\mathrm{Clb}$ ocorreu naturalmente sem que qualquer medida específica tenha sido adotada. O ressurgimento da doença, na década de 1980, esteve relacionado com a implantação e reforma de capineiras em larga escala para melhorar a alimentação dos animais. Na análise retrospectiva, realizada em 2003, pôde-se constatar que as capineiras naquela região continuavam a serem utilizadas, no entanto sem ampliação de áreas ou maiores reformas. Deste modo pode-se deduzir que, em situações nas quais os animais foram alimentados exclusiva ou predominantemente com forragem oriunda de áreas recentemente cultivadas, a concentração do fator desencadeante da Clb foi adequada para o aparecimento da doença.

Surtos de Clb em duas fazendas no Estado de São Paulo e as circunstâncias sob as quais a doença ocorreu, corroboram ainda as conclusões às quais se chegou pelas pesquisas realizadas. Na primeira fazenda, situada numa antiga área de ocorrência da Clb no município de Barretos, a doença incidiu novamente com a reforma simultânea, com aração, calagem e adubação, de todos os pastos da propriedade. Na segunda fazenda, situada no município de São Carlos, a Clb reapareceu, quando vacas e seus bezerros, mantidos num pasto "rapado" durante a época de seca, foram alimentados exclusiva ou predominantemente com cana-de-açucar de uma área recentemente reformada. (Dutra et al. 1993)

0 incentivo atual nas reformas de pastagens em áreas onde já uma vez ocorreu a Clb, deve levar em consideração a possibilidade do ressurgimento da doença. Por isso, no manejo de vacas com bezerros ao pé nas áreas reformadas, deve-se evitar que os animais se alimentem por longos períodos nestas pastagens. Da mesma forma, deve-se evitar o uso exclusivo ou predominante da forragem de capineiras recém-formadas. Mas convém frisar, que na interpretação de um possível benefício de qualquer medida de controle da Clb, sempre deve-se ter em mente a tendência natural do alcance de equilíbrio da microbiota do solo e a diminuição da produção de antibióticos, cuja maior concentração éfator desencadeante da doença. Assim, a prevalência da $\mathrm{Clb}$, em uma propriedade ou área, pode ser esquematizada sob forma de uma curva dinâmica, que, após ter subida abruptamente, declina em poucos anos em regiões de solos arenosos; mas pode declinar mais lentamente, após vários ou mesmo muitos anos, em áreas com solos argilosos. Então, para fazer interpretações fidedignas dos resultados de experimentação de campo, a seleção do grupo testemunha de bovinos com a periodontite da $\mathrm{Clb}$ sempre foi decisiva para se chegar a conclusões válidas no esclarecimento da etiologia da doença. Por outro lado, um suplemento mineral somente é eficaz no controle da periodontite quando contém um aditivo com ação antibiótica em concentração suficiente. Isto foi demonstrado experimentalmente com o uso de espiramicina e virginiamicina, visando profilaxia ou tratamento da periodontite (Döbereiner et al. 1990, Tims et al. 1992).

Pelos resultados de pesquisa obtidos, a $\mathrm{Clb}$ pode ser definida como periodontite epizoótica dos bovinos. Três fatores principais são necessários para sua ocorrência: (1) a presença de bactérias do grupo Bacteroides spp no espaço subgengival dos bovinos, (2) a ingestão de concentrações subinibitórias de antibióticos, oriundas de desequilíbrio da microbiota do solo, o que induz ao aumento da aderência dos bacteróides ao epitélio gengival, e (3) a idade dos animais, com os dentes prémolares e molares em fase de erupção.

Podemos concluir, que os surtos de Clb ocorreram em conseqüência de distúrbio drástico do meio ambiente decorrente do desmatamento e plantio direto de forrageiras, sem o cultivo prévio de culturas agrícolas nessas áreas; portanto, a utilização imediata destas áreas como pastagem e uso direto para gado de cria, estabeleceu as condições para o seu desencadeamento. 


\section{REFERÊNCIAS}

Baldani J.L., Baldani V.L.D., Xavier D.F., Boddey R.M.\& Döbereiner Joh. 1982. Efeito da calagem no número de actinomicetos e na porcentagem de bactérias resistentes a estreptomicina na rizosfera de milho. Revta Microbiologia, São Paulo, 13:250-263.

Blobel H., Döbereiner J., Lima F.G.F. \& Rosa I.V. 1984. Bacterial isolations from "cara inchada"-lesions of cattle. Pesq. Vet. Bras. 4(2):73-77.

Döbereiner J. \& Dämmrich K. 1997. Are alveolar changes a determinant factor for "cara inchada" in cattle? Pesq.Vet. Bras.17(2):45-48.

Döbereiner J., Inada T. \& Tokarnia C.H. 1974. "Cara inchada", doença peridentária em bovinos. Pesq. Agropec. Bras., Sér. Vet. 9:63-85.

Döbereiner J., Chaves J.A., Rosa I.V. \& Houser R.H. 1975. Efeito da transferência de bovinos com "cara inchada" (doença peridentária) para pastos de região indene. Pesq. Agropec. Bras., Sér. Vet. 10:99-103.

Döbereiner J., Rosa I.V. \& Lazzari A.A. 1976. "Cara inchada" (doença peridentária) em bezerros mantidos em pastos de Panicum maximum. Pesq. Agropec. Bras., Sér. Vet. 11:43-47.

Döbereiner J., Schenk J.A.P. \& Briso J.L. 1978. Experimento em bezerros afetados pela "cara inchada" (doença peridentária) em pasto formado sem emprego de fogo. XVI Congr. Bras. Med. Vet., Salvador, Bahia. (Resumo)

Döbereiner J., Rosa I.V. \& Lazzari A.A. 1987. Efeito do leite materno sobre as lesões peridentárias da "cara inchada" em bezerros. Pesq. Vet. Bras. 7(3):9799.

Döbereiner J., Rosa I.V., Dutra I.S., Pereira A.R. \& Blobel H. 1990. Efeito da espiramicina na profilaxia da "cara inchada" dos bovinos. Pesq. Vet. Bras. 10(1/2):27-29.

Döbereiner J., Dutra I.S., Rosa I.V. \& Blobel H. 2000. "Cara inchada" of cattle, an infectious, apparently soil antibiotic-dependant periodontitis in Brazil. Pesq. Vet. Bras. 20(2):47-64.

Dutra I.S. \& Döbereiner J. 1992. Efficacy of virginiamycin for the prophylaxis of "cara inchada", a periodontal disease of cattle. XIII Congr. Panam. Cienc. Veterinárias, Santiago, Chile, p.237.

Dutra I.S., Kanoe M. \& Blobel H. 1986. Atividades enzimáticas e endotóxicas de bactérias isoladas de lesões peridentárias da "cara inchada" dos bovinos. Pesq. Vet. Bras. 6(2):59-63.

Dutra I.S., Matsumoto T. \& Döbereiner J. 1993. Surtos de periodontite em bezerros ("cara inchada") associados ao manejo do solo. Pesq. Vet. Bras. 13(1):1-4.

Dutra I.S., Botteon R.C.M. \& Döbereiner J. 1999. Modificação da microbiota associada às lesões peridentárias da "cara inchada" em bezerros transferidos para área indene. Pesq. Vet. Bras. 20(2):71-74.
Giovine N., Rangel N., Machado A.V., Lamounier R.D. \& Wilwerth A. 1943. Necrobacilose. Súmula nosológica, a necrobacilose em Minas Gerais, Brasil. Arqs Esc. Sup.Vet. Minas Gerais 1:35-65.

Grassmann B., Döbereiner J., Dutra I.S., Kopp P.A. \& Blobel H. 1997. Adherence and experimental infection of bacteria associated with periodontal infections of young catte in Brazil ("cara inchada"). Pesq. Vet. Bras. 17(3):123-125.

Huddleston A.S., Cresswell N., Neves M.C.P., Beringer J.E., Baumberg S., Thomas D.I. \& Wellington E.M.H. 1997. Molecular detection of streptomycin producing streptomycetes in Brazilian soils. Appl. Environm. Microbiol. 63(4):1288-1297.

Kopp P.A., Dutra I.S., Döbereiner J., Schmitt M., Grassmann B. \& Blobel H. 1996. Estreptomicina aumenta a aderência em células epiteliais de Bacteroides melaninogenicus associado às lesões peridentárias da "cara inchada" dos bovinos. Pesq. Vet. Bras. 16(2):53-57.

Lamounier R.D. \& Pereira P.C. 1945. Sobre o caso de necrobacilose bovina em São Paulo, oriundo de um possível foco. Revta Fac. Med. Vet., São Paulo, 3:165-168.

Moraes S.S., Silva G.N. \& Döbereiner J. 1994. Microelementos minerais e a "cara inchada" dos bovinos. Pesq. Vet. Bras. 14(1):25-33.

Nunes V.A., Viana J.A.C., Carvalho A.U., Santos B.M., Ribeiro H.M. \& Teixeira T. 1979. Doença periodontal (cara inchada) em bovinos do Estado de Goiás. 1. Aspectos morfológicos. Arqs Esc. Vet. UFMG, Belo Horizonte, 31(3):283-296.

Page R.C. \& Schroeder H.E. 1982. Periodontitis in Man and Other Animals. A Comparative Review. Karger, Basel. 330 p.

Rosa I.V. \& Döbereiner J. 1994. "Cara inchada" dos bovinos e deficiências minerais. Pesq. Vet. Bras. 14(1):43-48.

Rosa I.V., Carvalho J.C., Houser \& Döbereiner J. 1976. Influência de ração balanceada sobre a "cara inchada" (doença peridentária) de bezerros. Pesq. Agropec. Bras., Sér. Vet 11:59-63.

Rosa I.V., Döbereiner J. \& Blobel H. 1985. O efeito de tratamento com antibióticos sobre as lesões peridentárias da "cara inchada" dos bovinos. Pesq. Vet. Bras. 5(1):5-9.

Seifert K., Walter P., Döbereiner J. \& Russel I. 1983. Histological investigations of "cara inchada" in cattle. Pesq. Vet. Bras. 3(2):67-70.

Shah H.N. \& Collins D.M. 1990. Prevotella, a new genus to include Bacteroides melaninogenicus and related species formerly classified in the genus Bacteroides. Int. J. Syst. Bacteriol. 40:205-208.

Tims F.M., Dutra I.S., Matsumoto T. \& Döbereiner J. 1992. Eficiência de virginiamicina na recuperação de bezerros com a doença peridentária "cara inchada". Pesq. Vet. Bras. 12(3):77-80. 